\title{
In situ underwater measurements of photosynthetic activity of coral zooxanthellae and other reef-dwelling dinoflagellate endosymbionts
}

\author{
P. J. Ralph ${ }^{1, *}$, R. Gademann ${ }^{2}$, A. W. D. Larkum ${ }^{3}$, U. Schreiber ${ }^{4}$ \\ ${ }^{1}$ Department of Environmental Sciences, University of Technology, Sydney, Westbourne St, Gore Hill, New South Wales \\ 2065, Australia \\ ${ }^{2}$ Gademann Meßtechnik, Dürrbachtal 232, D-97080 Würzburg, Germany \\ ${ }^{3}$ School of Biological Sciences, University of Sydney, New South Wales 2006, Australia \\ ${ }^{4}$ Julius-von-Sachs Institut für Biowissenschaften, Universität Würzburg, Mittlerer Dallenbergweg 64, D-97082 Würzburg, Germany
}

\begin{abstract}
Chlorophyll fluorescence was used to assess the in situ photosynthesis of a range of reefdwelling endosymbionts. Such non-intrusive in situ measurements became possible after the recent development of a submersible pulse modulated fluorometer (DIVING-PAM, Walz, Germany). Several corals, a clam (Tridacna maxima) and an anemone (Heteractis sp.) all showed strong chlorophyll a fluorescence signals originating from the dinoflagellate endosymbionts. Quenching analysis by the saturation pulse method revealed high quantum yields and light response curves characteristic of physiologically healthy sun plants. Rapid light curves (RLC) were applied to assess the light saturation behaviour of the different organisms in their rapidly changing natural environment. The 3 corals (Acropora aspera, Goniastrea sp. and Porites sp.), the clam T. maxima, and the anemone Heteractis sp. all showed high photosynthetic activity. The corals had a maximum electron transport rate of 180 to $270 \mu \mathrm{mol}$ electrons $\mathrm{m}^{-2} \mathrm{~s}^{-1}$, the Heteractis $\mathrm{sp}$. displayed a maximum rate of approximately $120 \mu \mathrm{mol}$ electrons $\mathrm{m}^{-2} \mathrm{~s}^{-1}$, whilst the $T$. maxima showed no saturation up to $1900 \mu \mathrm{mol}$ quanta $\mathrm{m}^{-2} \mathrm{~s}^{-1}$, where a rate of $325 \mu \mathrm{mol}$ electrons $\mathrm{m}^{-2} \mathrm{~s}^{-1}$ was observed. Three species of corals showed varying degrees of an apparent mid-day depression, occurring during the summer peak irradiance at low tide. Because quantum efficiency rapidly recovered during the afternoon period, when the irradiance levels decreased again, it is concluded from these preliminary investigations that the depression resulted mainly from down-regulation of photosystem II. Depth did not appear to influence the RLCs of $A$. aspera growing at 2,5 and $10 \mathrm{~m}$. Coral morphology influenced the apparent electron transport rate at different locations within a single colony
\end{abstract}

KEY WORDS: Symbionts $\cdot$ Chlorophyll fluorescence $\cdot$ Coral reef $\cdot$ Photosynthesis

\section{INTRODUCTION}

Chlorophyll fluorescence analysis by the so-called saturation pulse method has become a well-accepted technique for the assessment of plant stress and photosynthetic rates over the past $10 \mathrm{yr}$ (Schreiber et al. 1986, Genty et al. 1989, Krause \& Weis 1991). The relationship between the fluorescence yield and the quantum yield of energy conversion in photosystem II (PSII)

·E-mail: peter.ralph@uts.edu.au can be described by a simple equation which can be applied to estimate relative electron transport rate (ETR) (Genty et al. 1989). However, until recently such measurements were restricted to land plants or marine organisms that were transported to the surface, because of the lack of suitable instrumentation that could be taken underwater (Fitt \& Warner 1995, Franklin et al. 1996, Warner et al. 1996).

Coral reefs are of special interest for studies of photosynthesis and of the protective mechanisms against damage caused by photoinhibition, as they are shallow-water structures in the tropics and are therefore 
subject to high levels of insolation (Franklin et al. 1996). The structure of coral reefs is formed primarily by hermatypic corals that derive much of their carbon nutrition from the photosynthetic activities of their algal symbionts, zooxanthellae (dinoflagellate algae of the genus Symbiodinium) (Trench 1993).

The assessment of symbiont condition has previously been performed by enclosing samples of corals, or of other invertebrates containing photo-autotrophic endosymbionts, within a respirometer (Hoegh-Guldberg \& Smith 1989). This method is difficult to deploy in situ and is subject to technical difficulties. Perhaps the most important limitation is that oxygen production by the zooxanthellae cannot be accurately determined, as part of the synthesised oxygen is used for respiration by the symbiont and another part for the host's respiration (Kühl et al. 1995, Leletkin et al. 1996). Furthermore, while photoinhibition of photosynthesis (defined in the broad sense as either a damaging effect to photosynthesis or a down-regulation of the photosynthetic process, under high light) has been found in most reef algae at light levels $>1500 \mu \mathrm{mol}$ quanta $\mathrm{m}^{-2} \mathrm{~s}^{-1}$ (Franklin et al. 1996), most studies using respirometers have shown no depression of photosynthesis in coral under high light levels around midday. A possible exception here is the report of Titlyanov et al. (1991) where unstirred incubation jars were used. In view of the high photon flux density (PFD) levels generally experienced on a coral reef at mid-day in summer, a lack of photoinhibition would reflect the capacity of the system (damaged or not) to deliver sufficient reducing power to maintain photosynthesis. This high-light process might act together with a very effective mechanism for the dissipation of excess energy (down-regulation) in the absence of damage (Bjorkman \& Demmig-Adams 1994). The most plausible mechanism for down-regulation of photosynthesis under high light is currently the xanthophyll cycle mechanism which is known to be present in dinoflagellates (DemmigAdams \& Adams 1993).

With the recent advent of a submersible pulse modulated fluorometer (DIVING-PAM), relevant photosynthetic parameters, such as quantum yield and ETR can be measured in situ for the first time, thus opening the way for further investigations of photosynthetic properties of reef-dwelling endosymbionts in response to their light environment and to other ecophysiologically relevant parameters. A principal problem inherent in the assessment of ETR by in situ underwater measurements stems from the rapid water movements, which cause rapidly moving sun flecks, thus exposing the samples to largely varying quantum flux densities.

For the assessment of a given light state, which is mainly determined by the time of day and the constantly changing exposure to sun light, the automatic recording of so-called rapid light curves (RLC) has proven useful (Schreiber et al. 1997). Using samples which are already light-adapted to their natural environment, such RLCs can be recorded over a relatively short period of time ( 1 to $2 \mathrm{~min}$ ), i.e. much shorter than it takes, for example, for the xanthophyll cycle to be switched on or off ( 5 to $30 \mathrm{~min}$ ). This provides a reasonable approximation of the photosynthesis-irradiance $(P-I)$ relationship for this particular state of light adaptation. The 2 major parameters associated with common $P$ - $I$ curves are the light-saturated photosynthetic rate $\left(P_{\max }\right)$ and the initial slope of the curve $(\alpha)$. $P_{\max }$ provides an estimate of maximal photosynthetic capacity, while the initial slope of the $P$ - $I$ curve determines the maximal photochemical conversion efficiency (Falkowski \& Raven, 1997). However, in considering RLCs it should be realised that the RLC depends on the previous light history including transient responses (over $>5 \mathrm{~min}$ ) as well as on the duration of each light treatment during the determination (10 s). Only in a few cases have the fluorescence characteristics of algae been correlated with photosynthesis as measured by oxygen evolution, but where this has been done (Henley 1993, Schreiber et al. 1994) a good correlation has been obtained, showing that the equations originally derived from work on higher plants are also valid for algae. For the evaluation of RLC data, the following aspects are relevant:

(1) The samples were fully adapted to their natural environment, with light conditions being of primary importance. The RLC is intended to characterise this particular adaptation state.

(2) When incident light intensity changes due to a sun fleck or during the course of an RLC, unavoidably there are also changes of the induced light-state. However, such changes are slow with respect to the rapidly changing intensity (every $10 \mathrm{~s}$ during a RLC) (Schreiber et al. 1997), and, hence, it may be assumed that the RLC characteristics are mainly determined by the integrated state acquired during the long-term adaptation period (hours) preceding the RLC measurement.

(3) The ETR is calculated from the photochemical quantum yield and the incident PFD, with the assumption that a fixed amount of the incident quanta is absorbed and distributed to PSII. Presently there is no way to determine what part of the incident light is really reaching PSII in an individual sample. While this aspect requires caution in the interpretation of small differences between the RLCs of different species with differing morphology, it is of much less concern when RLCs of the same sample are compared, e.g. during the course of a day.

In this study we present the first in situ measurements of photosynthesis of zooxanthellae in shallow reef environments using chlorophyll fluorescence, and 
ask the questions: (1) What are the ranges of photosynthesis in these symbioses? (2) How does photosynthesis change throughout the day in these symbioses? (3) How is photosynthesis related to depth for the same symbiosis? and (4) How does shading affect the rate of photosynthesis in an individual coral colony?

\section{MATERIALS AND METHODS}

Sample site. All measurements of the various symbiont specimens were carried out at Heron Island, Great Barrier Reef (152 06' E, $20^{\circ} 29^{\prime}$ S). Water depth within the lagoon adjacent to the Heron Island Research Station ranged from 0.27 to $2.78 \mathrm{~m}$ during the sampling period. Goniastrea sp. was a massive coral, while Acropora aspera and the Porites sp. were branching corals. The Heteractis sp. anemone was maintained in the Heron Island Research Station flowthrough aquarium facilities, under shaded conditions

Fluorescence measurements. Chlorophyll fluorescence was measured with a DIVING-PAM Underwater Fluorometer (Walz, Germany), which like other pulseamplitude modulation (PAM) fluorometers employs $\mu \mathrm{s}$ pulses of measuring light $(650 \mathrm{~nm})$ for selective detection of the relative quantum yield of chlorophyll fluorescence. This instrument has been derived from the MINI-PAM fluorometer (Walz, Germany) which has been previously applied in numerous field studies of terrestrial plant photosynthesis. The rapid light curves (RLC) were measured automatically by the DIVINGPAM under the control of an internal program providing a sequence of actinic illumination periods, with light intensities increasing from 5 to $1500 \mu \mathrm{mol}$ quanta $\mathrm{m}^{-2} \mathrm{~s}^{-1}$ in 9 steps. Each illumination period lasted $10 \mathrm{~s}$ at the end of which time the maximum fluorescence yield was determined by a saturating pulse of white light $\left(800 \mathrm{~ms}\right.$ of $8000 \mu \mathrm{mol}$ quanta $\left.\mathrm{m}^{-2} \mathrm{~s}^{-1}\right)$ and the quantum yield was calculated according to the equation by Genty et al. (1989):

$$
\text { Quantum yield }=\left(\mathrm{Fm}^{\prime}-\mathrm{F}\right) / \mathrm{Fm}^{\prime}
$$

where Fm' is maximum fluorescence yield in the given light state, and $F$ is the steady state fluorescence yield in this particular state monitored briefly before the saturation pulse. On this basis the relative ETR was calculated as:

$$
\begin{aligned}
\mathrm{ETR}= & \text { quantum yield } \times \mathrm{PFD} \times 0.84 \times 0.5 \\
& \left(\mu \mathrm{mol} \text { electrons } \mathrm{m}^{-2} \mathrm{~s}^{-1}\right)
\end{aligned}
$$

where PFD is the photon flux density of photosynthetically active radiation (400 to $700 \mathrm{~nm}$ ), 0.84 is the assumed light absorbance of the sample, and 0.5 corrects for 2 quanta of light required for the transport of 1 electron. Underwater light intensity was measured at the upper surface of the coral colony by a fibre optic light sensor connected to the DIVING-PAM. The $\mathrm{Fv}^{\prime} / \mathrm{Fm}^{\prime}$ (where Fv' is the light-adapted variable fluorescence) ratios were derived from the first step of the RLC, where the ambient PFD was excluded for approximately $15 \mathrm{~s}$. Before the first saturating pulse of the RLC, the PSII reaction centres should be mostly open, providing an $\mathrm{Fv}^{\prime} / \mathrm{Fm}^{\prime}$ ratio related to the quantum yield of the ambient light state of the sample. Hence, these Fv'/Fm' ratios do not correspond to maximum quantum yield (Fv/Fm), determination of which would require 20 to 30 min dark adaptation. Maximum ETR was determined as the highest plateau region of the RLC.

The photosynthetic tissue must be shaded from ambient light during the RLC so that lower than ambient PFD can be applied. For this purpose, a black perspex block $(4.0 \times 5.0 \times 2.0 \mathrm{~cm})$ was used. The end of the fibre-optic light guide $(8 \mathrm{~mm}$ diameter) was mounted in the centre of this block, and the distance between the fibre head and surface of the block was recessed $5 \mathrm{~mm}$, to prevent coral damage to the optics. Given the irregular shape of corals, clams and other organisms, the fibre-optic mounting block had to be clamped in a fixed position during the measurement of the RLC. The perspex block was secured in position by 3 rubber bands with hooks. For a precise measurement of PFD, the distance between the fibre-optic's exit plane and the photosynthetic tissue sample should be constant, although this could not always be assured due to the irregular shape of some corals. An increase of $1 \mathrm{~mm}$ in the distance between the optics and the tissue resulted in a $1 \%$ reduction in light intensity and a corresponding overestimation of the ETR.

RLC for Tridacna maxima and Heteractis sp. Due to the rapid contraction of the clam's photosynthetic mantle, caution was required in attaching the fibre optics. Once the fibre-optic head was attached to the clam, with the mantle immediately below the fibre head, we waited until the clam gaped and completely exposed the mantle. After the first pulse of light, the mantle did not appear to retract. Epiphytic algae, mainly Enteromorpha intestinalis, covered most of the outer surface of the clam shell. To differentiate between the mantle tissue response and the epiphytic algae, several measurements were performed on the epiphytes remote from the mantle tissue. The anemone (Heteractis sp.) was maintained in a flow-through aquarium during these measurements. Chlorophyll fluorescence measurements were taken when the photosynthetic tissue was in contact with the glass aquarium wall, where the fibre optic to sample distance was $5 \mathrm{~mm}$

Diurnal RLC measurements of 3 corals. Sampling was performed at 2-hourly intervals on 3 tagged coral colonies (Acropora aspera, Goniastrea sp. and Porites 


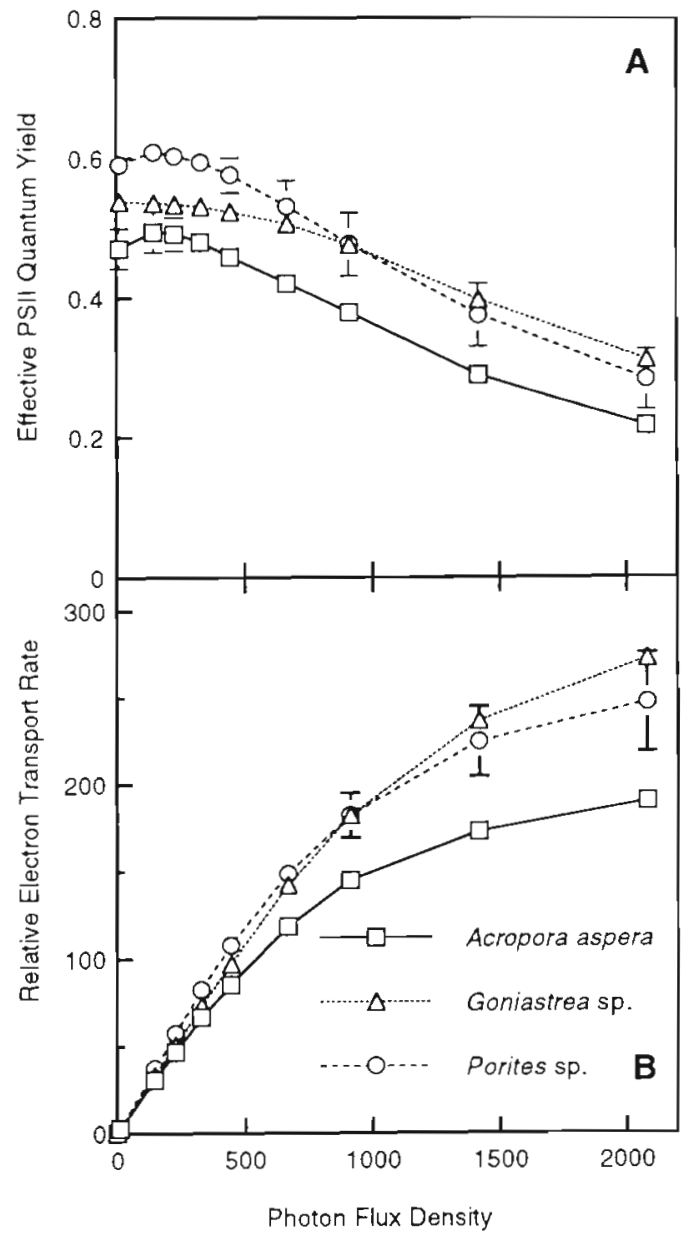

Fig. 1. In situ rapid light curves of $(A) \triangle F / F m$ ' and (B) ETR for Acropora aspera, Porites sp. and Goniastrea sp. from Heron Island. Sampled at 08:00 h when the PFD was $600 \mu$ mol quanta $\mathrm{m}^{-2} \mathrm{~s}^{-1}$. Error bars are $95 \%$ confidence intervals. Units of $\Delta F / \mathrm{Fm}^{\prime}$ were relative, units of electron transport rate were $\mu \mathrm{mol}$ electrons $\mathrm{m}^{-2} \mathrm{~s}^{-1}$ and units of PFD were $\mu \mathrm{mol}$ quanta $\mathrm{m}^{-2} \mathrm{~s}^{-1}$

sp.) on 8 December 1996. In situ repeated RLCs were measured at 3 random positions on the upper surface of each specimen. High tide occurred in the morning and evening and was approximately $2.78 \mathrm{~m}$, with extreme low tide at 13:00 h when only a few $\mathrm{cm}$ of water covered the top of the coral colonies. The average temperature was $26^{\circ} \mathrm{C}$. During the period of measurement there was no cloud cover until approximately 13:30 $\mathrm{h}$, when a rapid afternoon decline in PFD occurred. All measurements in this experiment were taken from the top of each specimen, the $A$. aspera and Porites sp. colonies were approximately $50 \mathrm{~cm}$ in diameter, while the Goniastrea sp. was about $20 \mathrm{~cm}$ in diameter.

Bathymetric measurements. Samples of Acropora aspera were measured at depths of 2,5 and $10 \mathrm{~m}$ at the Coral spawning dive site (SW reef rim).
Intra-colony measurements. Samples of 3 species of coral (Acropora aspera, Porites sp. and Goniastrea sp.) were measured in the lagoon adjacent to the Heron Island Research Station. Measurements were taken on the exposed upper surface of the colony and compared with a shaded lower region of the colony.

Statistical analysis. The difference between the maximum ETR measured on the exposed and shaded surfaces of the colonies were compared using an independent $t$-test. One-factor ANOVAs were used to compare the initial Fv'/Fm' ratios for the 3 coral species, for the Tridacna maxima clam, Heteractis sp., and Enteromorpha intestinalis, and for the bathymetric comparison of Acropora aspera.

\section{RESULTS}

Fig. 1 shows RLCs of 3 different corals which were recorded in situ on the Heron Island Reef at 08:00 $\mathrm{h}$ in the morning, when the PFD was $600 \mu$ mol quanta $\mathrm{m}^{-2}$ $\mathrm{s}^{-1}$. In Fig. $1 \mathrm{~A}$ a plot of effective PSII quantum yield $\left(\triangle F / F m^{\prime}\right)$ versus PFD is presented, whereas Fig. $1 B$ shows the corresponding plot of relative ETR versus $\mathrm{PFD}$. The 3 different coral species display quite similar, although not identical RLCs. The differences are most apparent in the $\triangle F / F m^{\prime}$ values at low PFD and the ETR-values at high PFD. None of these samples showed complete saturation of ETR. When compared to the light saturation responses of terrestrial plants (Schreiber \& Bilger 1993, Björkman \& Demmig-Adams 1994), such behaviour reflects the light adaptational state of extreme sun plants displaying exceptionally high capacity of photosynthetic electron flow. The branching coral (Porites sp.) showed the highest quantum yield at low quantum flux densities. For this coral a relatively high data variability was observed, which is a result of variations in the positioning of the fibre optic relative to the coral tissue. The morphology of Porites sp. did not lend itself to consistent fibre-opticto-sample distances, whereas Goniastrea sp, provided a relatively even surface; and with Acropora aspera it was possible to locate the fibre optic directly over the terminal region of an. upwardly-pointing branch. In the absence of actinic light, the $\mathrm{Fv}^{\prime} / \mathrm{Fm}^{\prime}$ ratios at 08:00 $\mathrm{h}$ for A. aspera, Goniastrea sp. and Porites sp. were $0.47 \pm$ $0.051,0.54 \pm 0.004$ and $0.59 \pm 0.019$, respectively. While these values are not particularly high, at least when compared to corresponding data for higher plant leaves (see e.g. Schreiber \& Bilger 1993), it should be considered that the corals were light-adapted at $600 \mu \mathrm{mol}$ quanta $\mathrm{m}^{-2} \mathrm{~s}^{-1}$ before the start of the RLC and that only a short time (15 s) was allowed for relaxation of non-photochemical fluorescence quenching, which reflects down-regulation of PS II quantum yield. 
In Fig. 2 the RLCs of 2 other endosymbiont containing organisms, the giant clam (Tridacna maxima) and the sea anemone (Heteractis sp.), are compared with the RLC of the macroalga Enteromorpha intestinalis growing as an epiphyte on the shell of the giant clam. Fig. $2 \mathrm{~A}$ shows plots of $\triangle F / F m^{\prime}$ versus $P F D$, while in Fig. $2 \mathrm{~B}$ the corresponding plots of ETR are displayed. Measurements with $T$. maxima and $E$. intestinalis. were carried out in situ at 10:30 h in the morning after adaptation to sunlight at an ambient PFD of $500 \mu \mathrm{mol}$ quanta $\mathrm{m}^{-2} \mathrm{~s}^{-1}$. On the other hand, the response of Heteractis sp. was assessed after keeping it for $2 \mathrm{~d}$ in a shaded seawater aquarium, and with an ambient PFD of $50 \mu \mathrm{mol}$ quanta $\mathrm{m}^{-2} \mathrm{~s}^{-1}$ observed shortly before start of the RLC. It is apparent that at low PFD the mantle of the giant clam displayed the lowest $\Delta \mathrm{F} / \mathrm{Fm}$ ', while the shade adapted Heteractis sp. was characterised by exceptionally high values. The $\mathrm{Fv}^{\prime} / \mathrm{Fm}^{\prime}$ ratio for the $T$. maxima, Heteractis sp. and the E. intestinalis were $0.40 \pm 0.097,0.69 \pm 0.013$ and $0.47 \pm 0.021$, respectively. In contrast, at high PFD the mantle of the clam showed the highest values of apparent quantum yield and of ETR, without any tendency for saturation up to $1900 \mu$ mol quanta $\mathrm{m}^{-2} \mathrm{~s}^{-1}$ (Fig. 2B). The epiphytes growing on this clam showed somewhat higher initial quantum yields, but were distinctly less efficient at higher PFD-values. And Heteractis sp. clearly displayed the lowest values of $\triangle \mathrm{F} / \mathrm{Fm}$ ' and of ETR at high PFD, with ETR being saturated at a level amounting to less than $50 \%$ of the value observed for $T$. maxima.

These data suggest that the combined information from RLCs of effective quantum yield, $\triangle F / F m^{\prime}$, and of relative electron transport rate, ETR, provides a rapid means for assessment of photosynthetic performance of plants in their natural environment. Plots of $\Delta F / F^{\prime}$ are much more sensitive to differences in quantum yield in the low-PFD range than plots of ETR (compare Fig. 2A and B).

From an ecophysiological point of view, the aspect of changing photosynthetic capacity during the course of a day is of particular interest. Fig. 3 shows the result of a preliminary diurnal experiment performed with 3 different corals in situ. During this experiment the irradiance increased from virtual darkness in the case of the pre-dawn measurements $(04: 00 \mathrm{~h})$ to a peak PFD of $2200 \mu \mathrm{mol}$ quanta $\mathrm{m}^{-2} \mathrm{~s}^{-1}$ at around $12: 00 \mathrm{~h}$, and then declined during the afternoon, until sunset at 18:00 h. All 3 corals first showed a rise of maximum ETR, which was followed by a significant depression, starting surprisingly early in the day (approximately 08:00 h), with minimum values around 12:00 h and maximal recovery occurring at about 16:00 h. Thereafter, the maximal ETR declined again when sunset was approached. Acropora aspera showed the highest sensitivity to light as indicated by the greatest decline in maximum ETR,

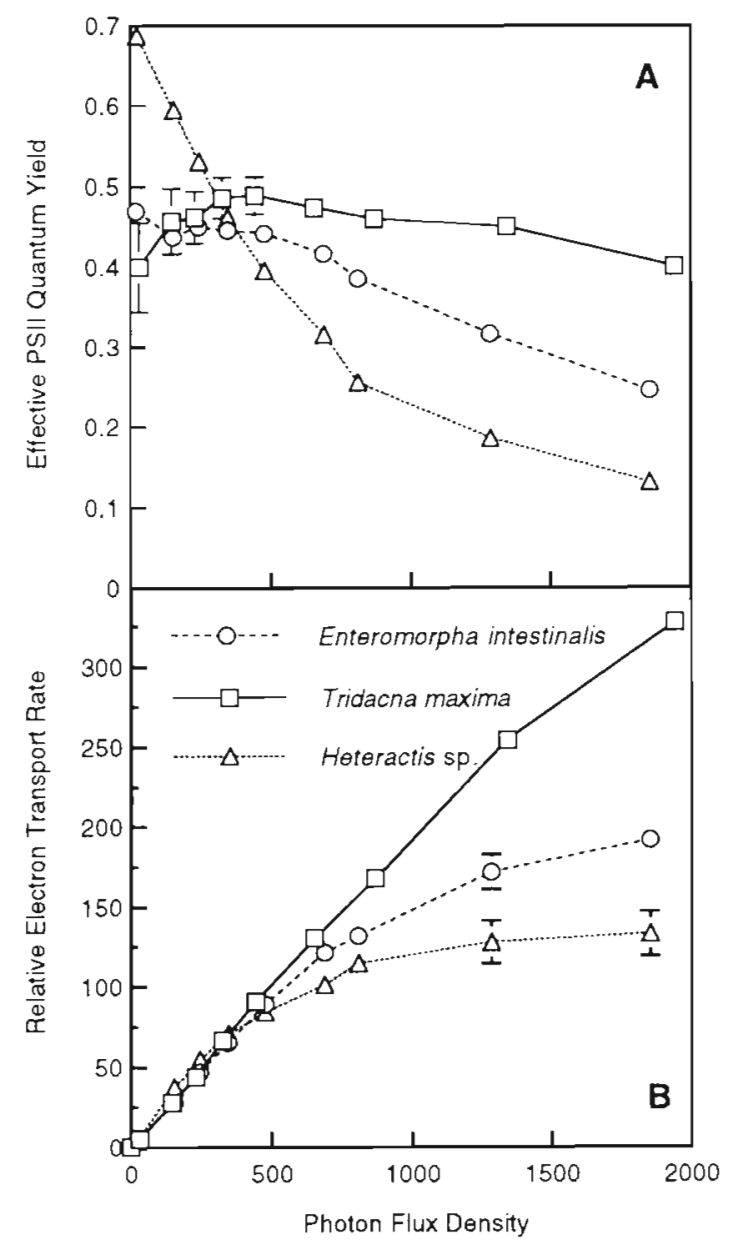

Fig. 2. In situ rapid light curves of (A) $\Delta \mathrm{F} / \mathrm{Fm}^{\prime}$ and (B) ETR for Tridacna maxima, Enteromorpha intestinalis and an Heteractis sp. anemone. Error bars are $95 \%$ confidence intervals. Units of $\Delta \mathrm{F} / \mathrm{Fm}$ ' were relative, units of electron transport rate were $\mu \mathrm{mol}$ electrons $\mathrm{m}^{-2} \mathrm{~s}^{-1}$ and units of of PFD were $\mu \mathrm{mol}$ quanta $\mathrm{m}^{-2} \mathrm{~s}^{-1}$

and Porites sp. the least. The Fv'/Fm' ratios for the diurnal experiment complemented the response curves of maximum ETR. It is apparent that the midday depression of maximum ETR is correlated with a lowering of the quantum yield of open PSII reaction centres. The afternoon recovery of $A$. aspera reached the same level of ETR as the morning peak, whereas the Goniastrea sp. and Porites sp. afternoon peaks were lower than the morning peaks. For all 3 corals the lowest maximum ETR during the daylight period occurred at mid-day, during maximum PFD exposure. Although only 1 set of data are presented here, comparable data were collected on a number of other similar days.

In Fig. 4, rapid light curves of Acropora aspera growing at different depths on the reef are compared. The samples from the lower slope of the reef $(10 \mathrm{~m}$; 

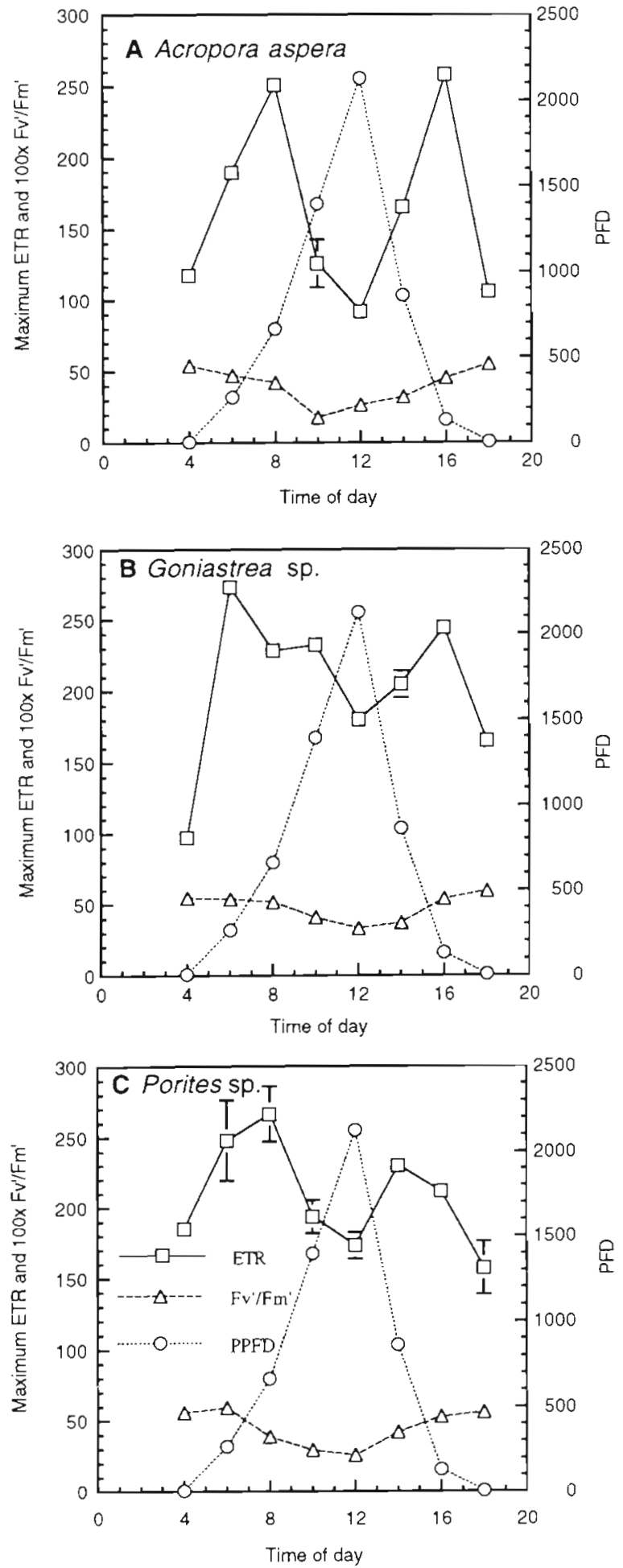

Fig. 3. In situ diumal changes in maximum ETR and Fv'/Fm' ratio for 3 corals (A) Acropora aspera, (B) Goniastrea sp. and (C) Porites sp. from Heron Island. Error bars are $95 \%$ confidence intervals. Units of electron transport rate were umol electrons $\mathrm{m}^{-2} \mathrm{~s}^{-1}$ and units of PFD were $\mu \mathrm{mol}$ quanta $\mathrm{m}^{-2} \mathrm{~s}^{-1}$ $\mathrm{Fv}^{\prime} / \mathrm{Fm}^{\prime}$ values were measured following $15 \mathrm{~s}$ sample darkening (see 'Materials and methods')

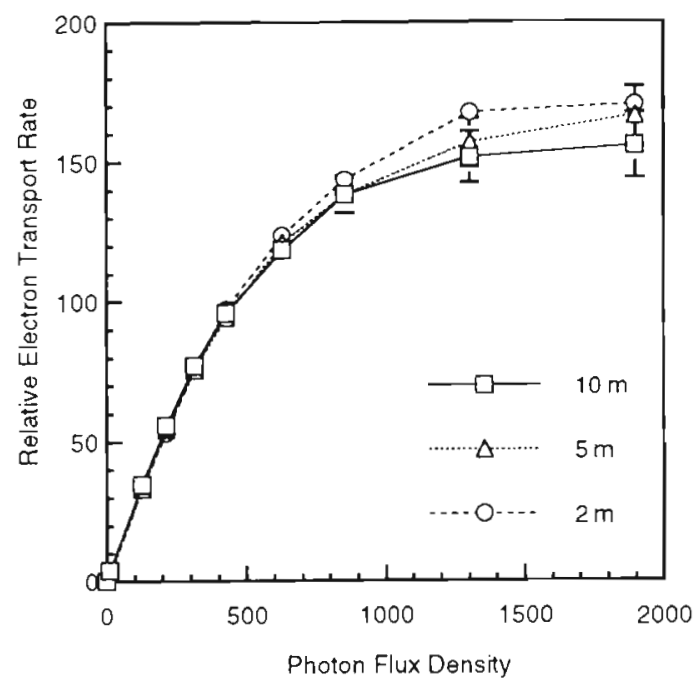

Fig. 4. Comparison of in situ rapid light curves for Acropora aspera at 3 depths; 10, 5 and $2 \mathrm{~m}$. Error bars are $95 \%$ confidence intervals. Units of electron transport rate were $\mu \mathrm{mol}$ electrons $\mathrm{m}^{-2} \mathrm{~s}^{-1}$ and units of PFD were $\mu \mathrm{mol}$ quanta $\mathrm{m}^{-2} \mathrm{~s}^{-1}$

$100 \mu \mathrm{mol}$ quanta $\left.\mathrm{m}^{-2} \mathrm{~s}^{-1}\right)$, the mid-slope $(5 \mathrm{~m} ; 215 \mu \mathrm{mol}$ quanta $\mathrm{m}^{-2} \mathrm{~s}^{-1}$ ) and the reef rim ( $2 \mathrm{~m} ; 350 \mu \mathrm{mol}$ quanta $\mathrm{m}^{-2} \mathrm{~s}^{-1}$ ) showed only minor differences in their RLCs. The initial slopes were identical, while maximum ETR decreased slightly with depth. The Fv'/Fm' ratios for the $A$. aspera bathymetric profile from 10,5 and $2 \mathrm{~m}$ were $0.67 \pm 0.045,0.64 \pm 0.027$ and $0.64 \pm 0.069$ respectively. The ANOVA was unable to detect a difference between the $\mathrm{Fv}^{\prime} / \mathrm{Fm}^{\prime}$ ratios from different depths $\left(F_{(2,6)}=0.470, \mathrm{p}=0.646\right)$.

Under moderate light conditions there was a signifjcant $(p<0.05)$ intra-colony variation, between the maximum ETR of the exposed and shaded surfaces of 2 of the branched corals (Table 1). Ambient PFD was approximately $400 \mu \mathrm{mol}$ quanta $\mathrm{m}^{-2} \mathrm{~s}^{-1}$ on the exposed and $<100 \mu$ mol quanta $\mathrm{m}^{-2} \mathrm{~s}^{-1}$ on the shaded surfaces of the colonies. No significant difference in ETR was found between the exposed and shaded surface of the massive coral, Goniastrea sp.; however, the shade versus exposed surfaces of all 3 species were found to be different with respect to the $\mathrm{Fv}^{\prime} / \mathrm{Fm}^{\prime}$ ratio.

\section{DISCUSSION}

\section{Photosynthetic capacity of various zooxanthellae}

A major conclusion of the present study is that the symbionts in the studied organisms displayed high photosynthetic activity in situ. Indeed, it proved impossible to saturate some of the symbionts at the maximum quantum flux density available with the DIVING-

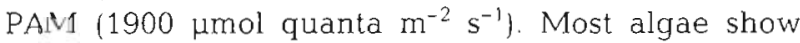


Table 1 Comparison of the maximum ETR and the Fy'/Fm' ratio from the exposed and shaded surfaces of 3 corals: Acropora aspera, Goniastrea sp. and Porites sp. from Heron Island. Measurements are means \pm standard errors $(\mathrm{n}=6)$, and units for ETR are $\mu \mathrm{mol}$ electrons $\mathrm{m}^{-2} \mathrm{~s}^{-1}$, and $\mathrm{Fv} / \mathrm{Fm}$ ' ratio are relative ' ' Significant difference at $\mathrm{p}<0.05$

\begin{tabular}{|c|c|c|c|c|}
\hline & Exposed surface & Shaded surface & $t$-test & $p$-value \\
\hline \multicolumn{5}{|l|}{ Maximum ETR } \\
\hline A. aspera & $227.83 \pm 19.71$ & $152.67 \pm 17.08$ & 6.199 & $0.002 \cdots$ \\
\hline Goniastrea sp. & $198.67 \pm 5.99$ & $194.33 \pm 9.05$ & 0.657 & 0.540 \\
\hline Porites sp. & $242.50 \pm 32.67$ & $146.67 \pm 11.38$ & 5.256 & $0.003 \cdots$ \\
\hline \multicolumn{5}{|l|}{$\mathrm{Fv}^{\prime} / \mathrm{Fm}^{\prime}$ ratio } \\
\hline A. aspera & $0.44 \pm 0.046$ & $0.64 \pm 0.008$ & 10.445 & $0.000 \cdots$ \\
\hline Goniastrea sp. & $0.47 \pm 0.024$ & $0.61 \pm 0.018$ & 10.320 & $0.000 \cdots$ \\
\hline Porites sp. & $0.46 \pm 0.015$ & $0.55 \pm 0.079$ & 3.080 & $0.012 \cdots$ \\
\hline
\end{tabular}

characteristics of shade plants (Larkum \& Barrett 1983) however, compared to published $P$-I curves for terrestrial plants (Björkman \& Demmig-Adams 1994), the present curves indicate an adaptation to high light, with the exception of the anemone, due to its shaded environment in the outdoor aquarium. As a consequence of the relatively short illumination period during the RLC, the values of $\alpha$ and $P_{\max }$ may be underestimated (as insufficient time for photosynthetic equilibration). If the RLC underestimated the photosynthetic response, this would result in a shift towards shade adaptation, further supporting the conclusion that these reef symbionts display properties of extreme sun plants. The high photosynthetic capacity can be considered to be the result of effective adaptation to the high-light conditions on the reef. It also may be taken as evidence for a healthy physiological state of the organisms assessed. In addition, 2 major factors that often limit maximum assimilation rates in terrestrial plants are lacking in the aquatic endosymbionts: first, there is no limitation due to stomatal control of $\mathrm{CO}_{2}$-supply under the influence of water stress; and second, due to the permanent export of assimilates to the host it appears unlikely that there is any sink limitation. Nevertheless at high light intensities there was a saturation of photosynthesis with the exception of Tridacna maxima. Kühl et al. (1995) found high diffusive boundary layers for oxygen at the surface of polyps under these conditions. This suggests that similar diffusive boundary layers exist for inorganic carbon species under similar condition (the diffusion coefficients are all similar) which would mean that supply of inorganic carbon for photosynthesis can become limiting under high light intensities. Dubinsky et al. (1990) also found competition for $\mathrm{CO}_{2}$ occurred with high algal densities at high photosynthetic rates under saturating irradiance.

High electron transport capacity may be considered an important factor for protection against photoinhibition in the sense of photodamage to PSII. Several recent papers have found no evidence of photoinhibition in corals (Davies 1991, Patterson et al. 1991, Kinzie 1993). The situation is complicated by the fact that photoinhibition in the broad sense may be due either to damage or a down-regulation of photosynthesis through the xanthophyll cycle with energy dissipation as heat. Furthermore, high levels of PFD normally are concurrent with elevated levels of potentially injurious UV. Lesser (1996) demonstrated a reduction in PSII quantum yield with cultured Symbiodinium bermudense by elevated temperature and UV exposure. While our data do not show any evidence for damage, they clearly indicate down-regulation of PSII by dissipation of excess light energy and thus support the presence of dynamic photoinhibition, in the broad sense, in corals.

In the evaluation of the data it should be noted that the chlorophyll a fluorescence technique preferentially samples the cells at the surface of the photosynthetic tissue and their associated zooxanthellae. Cells located lower in the tissue are likely to show a tendency towards shade behaviour. A similar situation occurs with the epilithic algal community of coral reefs (Franklin et al. 1996). Clearly, this requires further investigation and further technical advances, such as microfibre measuring systems (Klimant et al. 1995, Schreiber et al. 1996) which allow the assessment of photosynthesis in deeper tissue layers. Such a system, so far, does not exist for underwater measurements. A principal problem of comparing our fluorescence results with previous results based on oxygen evolution is that fluorescence generally assesses the charge separation rate at PSII which, however, does not necessarily correspond to the rate of $\mathrm{O}_{2}$-evolution. Recently, $\mathrm{O}_{2}$-dependent electron flow in the so-called Mehler-Ascorbate-Peroxidase Cycle has been suggested as playing a role in the regulated dissipation of excess light energy (Schreiber \& Neubauer 1990, Schreiber et al. 1995, Park et al. 1996j. This cycle is characterised by zero net oxygen exchange and the capability of creating a large trans-thylakoidal proton gradient, which again has the potential to down-regulate PSII quantum yield. Another type of electron flow 
that is not paralleled by $\mathrm{O}_{2}$-evolution, is cyclic transport around PSII (Prasil et al. 1996). Furthermore, as already pointed out above, it has to be considered that measurements of $\mathrm{O}_{2}$-evolution are complicated by $\mathrm{O}_{2}$ uptake, due to respiration of endosymbionts and host.

The light response curve of the Tridacna maxima (Fig. 2B) demonstrates that photosynthesis can be measured effectively by the fluorescence technique in this organism, and that the symbiotic association was well-adapted to high-light conditions. However, the light-absorbing properties of the $T$. maxima mantle may well influence the RLC response, as the brilliantly green, blue, red, violet and brown pigments could effectively filter much of the incident irradiance. The effect of filtering would result in an overestimation of the photosynthetic activity. The presence of a range of light absorbing pigments would also influence the capacity of the $T$. maxima symbiont to photosynthesise at greater depths. If the pigment density was not modified, the clam would suffer from reduced carbon fixation at depths, where the light intensity is below the compensation point.

\section{Mid-day depression of photosynthetic activity}

All 3 corals showed a depression in photosynthesis during the periods of peak irradiance around mid-day, as seen by a decline in maximum ETR. Acropora aspera showed the most obvious mid-day depression and the most pronounced recovery which was complete by 16:00 h. Such rapid and complete recovery of maximum ETR gives clear evidence that the depression involved an active down-regulation, as a protective response to elevated PFD (Björkman \& DemmigAdams 1994, Schreiber et al. 1994). It is possible that damage occurred; this would be seen as a decrease in $\alpha$ in the RLCs. Obviously, there are 2 opposing effects of light on the maximum ETR observed in a RLC. During the early morning and in the late afternoon, the endosymbionts are partially dark-adapted which means that Calvin cycle enzymes are partially darkinactivated. This is reflected by low values of maximal ETR during a RLC, as illumination times during a RLC are too short to allow significant changes of the light adaptation state. On the other hand, during the major part of the day (08:00 to 16:00 h) the endosymbionts are fully light-adapted and exposed to excess light, as they appear to be in a down-regulated state, analogous to the well-known mid-day depression of terrestrial plants (Demmig-Adams et al. 1989). As mentioned in the 'Introduction', it takes 5 to 30 min to switch on down regulation by the xanthophyll cycle and this is much longer than the $90 \mathrm{~s}$ it takes to do a RLC. The increased variation of the Porites $\mathrm{sp}$. diurnal measure- ments could be attributed to the sampling inconsistency (varying fibre-optic-to-sample distances) with its morphological form, as mentioned earlier.

\section{Bathymetric investigation}

The in situ irradiance at a depth of 10 or $5 \mathrm{~m}$ is different in both intensity and quality to the shallow $2 \mathrm{~m}$ sample site. Furthermore, the photosynthetic capacity of the coral symbiont is dependent upon the zooxanthellae density and polyp diameter. One would expect the deeper corals to show somewhat more shadeadapted responses, with a lower $P_{\max }$ (or maximum ETR) and higher $\alpha$ (Chalker et al. 1983). However, Fig. 4 shows only small differences in the rapid light curves, with only a small tendency in the expected direction. Some form of compensatory photo-acclimation may have occurred through changes in photosynthetic electron transport chains (thylakoid area) or chloroplast density or symbiont density (Larkum \& Barrett 1983, Trench 1993).

\section{Intra-colony variation}

Large coral colonies will have different micro-environments (light, exposure and current), causing intracolony variation in photosynthetic activity. The coral morphology and direction (horizontal or angled) dictate the degree of self-shading, with branched corals causing greater shading of the lower regions than the massive (Goniastrea sp.) corals (Table 1). The lowering of the Fv'/Fm' in the sun exposed part of the Goniastrea sp. specimen resulted from down-regulation of maximal PSII quantum yield during strong illumination. Only part of the related non-photochemical quenching will 'relax' during the short (15 s) dark-time before the Fv'/Fm' measurement. This is an interesting observation since it is not immediately apparent that the level of branching in such species as Acropora aspera would create such reductions in light field. The apparent intra-colony variation has implications for the selection of sample positions within a single coral colony in any further investigations. The branching corals increase shading of other colonies, as well as the lower region of the same colony (Chalker et al. 1983).

In conclusion our investigation demonstrates the capacity of the new DIVING-PAM chlorophyll fluorometer to assess the in situ photosynthetic rates of reef-dwelling symbionts. The demonstration of a midday depression in the photosynthetic activity of a range of corals is the best example of the utility of this new approach in uncovering important processes which have not been generally recognised previously. 
Acknowledgements. We thank Dr Bill Dennison and the Heron Island Research Station research and support staff for their assistance during our visit and Dr D. Morrison for editorial comment. ARC Institutional Grant funding to A.W.D.L. supported this work, and U.S acknowledges the support of the Deutsche Forschungsgemeinschaft (SFB 176 and 251).

\section{LITERATURE CITED}

Björkman O, Demmig-Adams B (1994) Regulation of photosynthetic light energy capture, conversion, and dissipation in leaves of higher plants. In: Schulze ED, Caldwell MM (eds) Ecophysiology of photosynthesis ecological studies, Vol 100, Springer, Berlin, p 49-70

Chalker BE, Dunlap WC, Oliver JK (1983) Bathymetric adaptations of reef-building corals at Davies Reef, Great Barrier Reef, Australia. II Light saturation curves for photosynthesis and respiration. J Exp Mar Biol Ecol 73: $37-56$

Davies PS (1991) Effect of daylight variations on the energy budgets of shallow-water corals. Mar Biol 108:137-144

Demmig-Adams B, Adams WW III (1993) The xanthophyll cycle. In: Young A, Britton G (eds) Carotenoids in photosynthesis. Chapman \& Hall, London, p 206-251

Demmig-Adams B. Adams WW III, Winter $K$, Meyer $A$, Schreiber U, Pereira JS, Kruger A, Czygan FC, Lange OL (1989) Photochemical efficiency of photosystem II, photon yield of $\mathrm{O}_{2}$ evolution, photosynthetic capacity, and carotenoid composition during the midday depression of net $\mathrm{CO}_{2}$ uptake in Arbutus unedo growing in Portugal. Planta 177:377-387

Dubinsky Z, Stambler N, Ben-Zion M, McCloskey LR, Muscatine L, Falkowski PG (1990) The effect of external nutrient resources on the optical properties and photosynthetic efficiency of Stylophora pistillata Proc R Soc Lond B 239: $231-246$

Falkowski PG, Raven JA (1997) Aquatic photosynthesis Blackwell Science, Massachusetts

Fitt WK, Warner ME (1995) Bleaching patterns of four species of Caribbean corals. Biol Bull 189:298-307

Franklin LA, Seaton GGR, Lovelock CA, Larkum AWD (1996) Photoinhibition of photosynthesis on a coral reef. Plant Cell Environ 19:825-836

Genty B, Briantais JM, Baker NR (1989) The relationship between the quantum yield of photosynthetic electron transport and quenching of chlorophyll fluorescence Biochim Biophys Acta 990:87-92

Henley WJ (1993) Measurement and interpretation of photosynthetic light-response curves in algae in the context of photoinhibition and diurnal changes. J Phycol 29: $729-739$

Hoegh-Guldberg O, Smith GJ (1989) The effect of sudden changes in temperature, light and salinity on the population density and export of zooxanthellae from the reef corals Stylophora pistillata Esper and Seriatopora hystrix Dana. J Exp Mar Biol Ecol 129:279-303

Kinzie RA III (1993) Effects of ambient levels of solar ultraviolet radiation on zooxanthellae and photosynthesis of the reef coral Montipora verrucosa. Mar Biol 11,6:319-327

Klimant I, Meyer V, Kühl M (1995) Fiber-optic oxygen microsensors, a new tool in aquatic biology. Limnol Oceanogr 40:1159-1165

Editorial responsibility: George Humphrey (Contributing Editor), Sydney, Australia
Krause GH, Weis E (1991) Chlorophyll fluorescence and photosynthesis: the basics. Annu Rev Plant Physiol 42: 313-349

Kühl M, Cohen Y, Dalsgaard T, Jorgensen BB, Revsbech NP (1995) Microenvironment and photosynthesis of zooxanthellae in scleractinian corals studied with microsensors for $\mathrm{O}_{2}, \mathrm{pH}$ and light. Mar Ecol Prog Ser 117:159-172

Larkum AWD, Barrett J (1983) Light-harvesting processes in algae. Adv Bot Res 10:1-221

Leletkin VA, Titlyanov EA, Dubinsky Z (1996) Photosynthesis and respiration of the zooxanthellae in hermatypic corals habitated on different depths of the Gulf of Filat. Photosynthetica 32:481-490

Lesser MP (1996) Elevated temperatures and uitraviolet radiation cause oxidative stress and inhibit photosynthesis in symbiotic dinoflagellates. Limnol Oceanogr 41:271-283

Park YI, Chow WS, Osmond CB, Anderson JM (1996) Electron transport to oxygen mitigates against photoinactivation of photosystem II in vivo. Photosyn Res 50:23-32

Patterson MR, Sebens KP, Olson RR (1991) In situ measurements of flow effects on primary production and dark respiration in reef corals. Limnol Oceanogr 36:936-948

Prasil O, Kolber Z, Berry JA, Falkowski PG (1996) Cyclic electron flow around photosystem II in vivo. Photosyn Res 48 : 395-410

Schreiber U, Bilger W (1993) Progress in chlorophyll fluorescence research: major developments during the last years in retrospect. Prog Bot 54:151-173

Schreiber U, Neubauer $\mathrm{C}$ (1990) $\mathrm{O}_{2}$-dependent electron flow, membrane energisation and the mechanism of non-photochemical quenching of chlorophyll fluorescence. Photosyn Res 25: 279-293

Schreiber U, Schliwa U, Bilger W (1986) Continuous recording of photochemical and non-photochemical chlorophyll fluorescence quenching with a new type of modulation fluorometer. Photosyn Res 10:51-62

Schreiber U, Bilger W, Neubauer C (1994) Chlorophyll fluorescence as a non-intrusive indicator for rapid assessment of in vivo photosynthesis. In: Schulze ED, Caldwell MM (eds) Ecophysiology of photosynthesis ecological studies, Vol 100. Springer, Berlin, p 49-70

Schreiber U, Hormann H, Neubauer C, Klughammer C (1995) Assessment of photosystem II photochemical quantum yield by chlorophyll fluorescence quenching analysis Aust J Plant Physiol 22:209-220

Schreiber U, Kühl M, Klimant I, Reising H (1996) Measurement of chlorophyll fluorescence within leaves using a modified PAM fluorometer with a fiber-optic microprobe Photosyn Res 47:103-109

Schreiber U, Gademann R, Ralph PJ, Larkum AWD (1997) Assessment of photosynthetic performance of Prochloron in Lissoclinum patella in hospite by chlorophyll fluorescence measurements. Plant Cell Physiol 38(8):945-951

Titlyanov EA, Butorin PV, Leletkin VA, Le Nguyen Hieu (1991) Diurnal changes in the structure and function of the respiratory intensity of mass species of corals of Vietnam. Biol Mora (Vladivostok) 17:172-179

Trench RK (1993) Microalgal-Invertebrate symbioses: a review. Endocytobiosis Cell Res 9:135-175

Warner ME, Fitt WK, Schmidt GW (1996) The effects of elevated temperature on the photosynthetic efficiency of zooxanthellae in hospite from four different species of reef coral: a novel approach. Plant Cell Environ 19:291-299

Submitted: June 15, 1997; Accepted: November 20, 1998

Proofs received from author(s): April 1, 1999 